of at least 150 miles in diameter, and were no doubt produced by a huge exploding fireball. The morning in question was clear and bright. E. G. Fenton.

Rio Gallegos, Patagonia, February 12.

\section{On the Gain of Definition obtained by Moving a} Telescope.

Is not the case mentioned by M. E. J. Gheury in Nature of March 27 (p. 86) but a special case of the familiar fact that an object which is so like its background as to be invisible when at rest is commonly visible when it moves? In this case, as the telescope moved, the signal in its field of view was to the eye fixed to its eyepiece an object moving against the background of misty sky, which it so nearly resembled as to be invisible when at rest. Is not the

\section{NORTHERN METHODS OF BURIAL IN THE IRON $A G E$.}

M R. SCHETELIG'S excellent memoir ${ }^{1}$ describes the recent more precise investigations which correct and elucidate older work. Relics other than from graves are insignificant, and the nominal restriction to Vestland scarcely lessens the interest, for local discoveries are throughout compared with those in other provinces and countries. Neither a catalogue raisonné of antiquities, nor a general account of the evolution of Norwegian culture during the Iron Age, the volume serves as a foundation for works of those

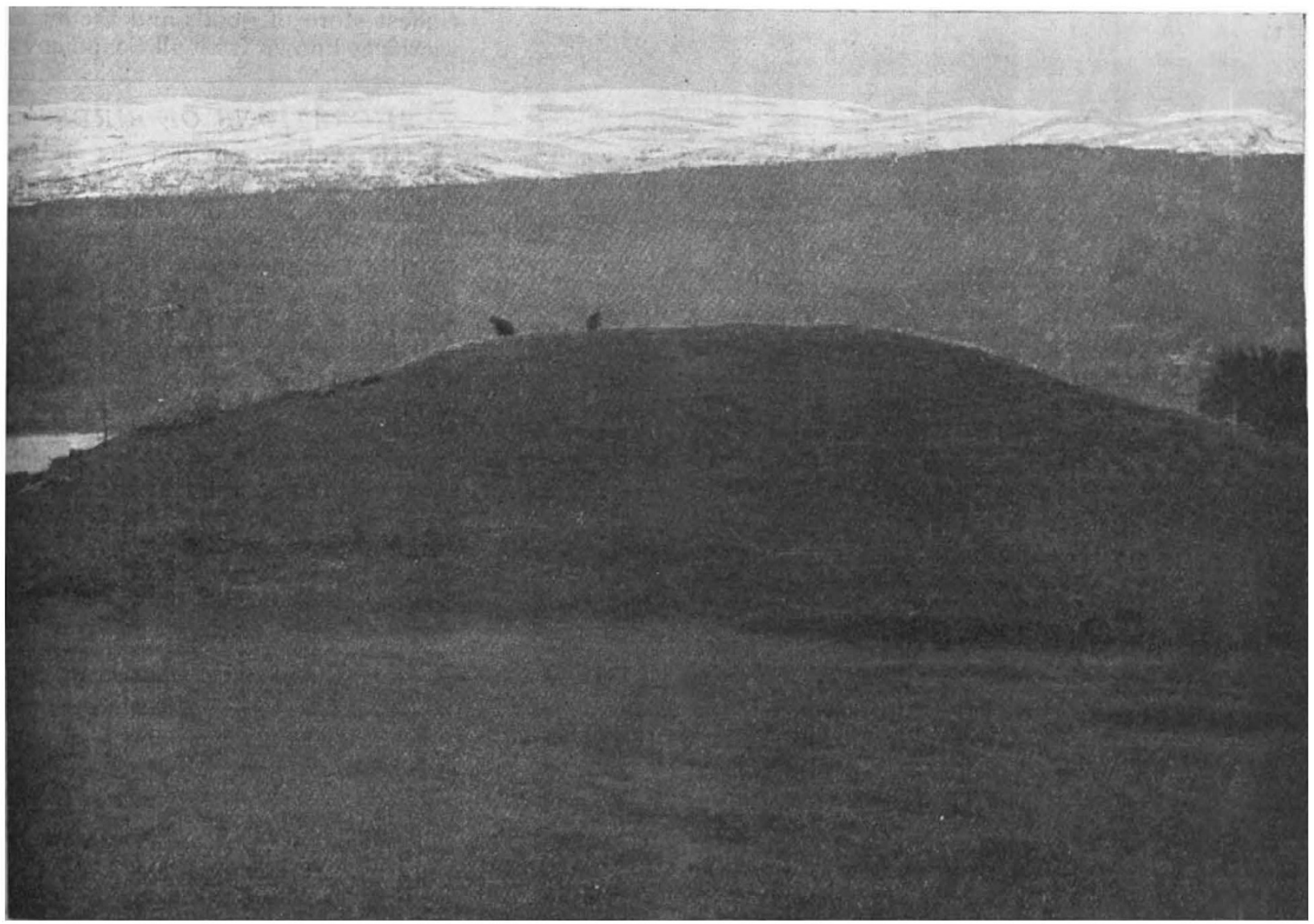

FIG. I.-The Byrkje grave-mound at the beginning of the excavation. From "Vestlandske Graver fra Jernalderen." Bergens Musetims Skrifter.

explanation as follows? Visibility of the object, and in particular of its outline, depends on contrast between it and its background. There is commonly some contrast, but often so slight as not to attract attention when the object is at rest. When, however, the object moves, the brain receives successive impressions of contrast as the image of the object falls on one part of the retina after another. Thus the brain receives a cumulative impression of contrast between the object and the background, and the object becomes "visible."

If this be not, as perhaps it is not, a perfect explanation of this familiar fact, there are probably many others beside myself who will be glad to know what the correct explanation is.

Candahar, Reigate.

G. W. Butler. two different classes. The objective account of the graves themselves, and of the disposition therein of the varied remains, is its endeavour; and its general conclusions relate mainly to the development of burial methods.

The third and fourth centuries A.D. are, in Vestland as elsewhere, those most influenced by Roman culture, while during the fifth and sixth centuries more original lines were followed. During the third century, however, a greater change occurred than about the year 400 ; it was

l "Bergens Museums Skrifter." Ny Raekke. Bd. ii. No. I. Vestlandske Graver fra Jernalderen. By Haaknn Schetelig. Pp. iiit 242. (Bergen : A/S John Griegs Boktrykkeri, I9'2.) 
also before the latter date that Vestland entered into relations with the West Germanic civilisation on the east coast of the North Sea, and the AngloSaxon on its west coast.

Burials without cremation first occurred in the northern countries during the Roman period, and with a broadening of culture the funeral furniture grew more elaborate and diverse. These changes, entering Vestland later than other parts of Scandinavia, affected also the cremation burials, and in the Folk-wandering period (400-800 A.D.) the two kinds tended to fuse. Thus both methods occur in a grave-mound with three graves at Byrkje in Voss (Fig. I). One of these graves, that of a

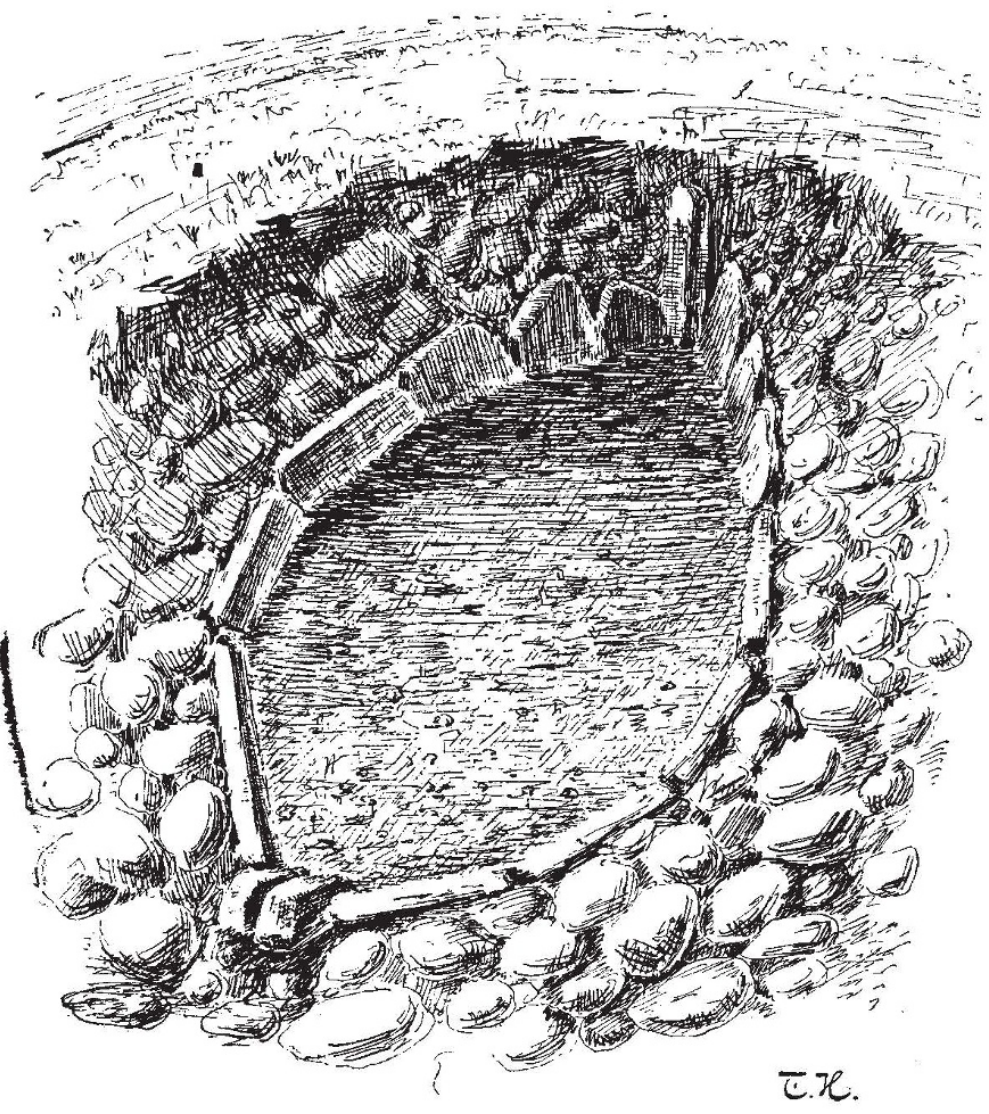

FIG. 2. - A boat-shaped arrangement of stones round a cremation-burial at $\varnothing \mathrm{lb} \phi \mathrm{r}$; a wooden boat also formed part of the pyre. (After T. Helliesen, Stavanger Mus. Aarsh., rgoz) boat also formed part of the pyre. (After T. Helliesen, Stavanger Mus.
From "Vestlandske Graver fra Jernalderen." Bergens Museums Skrifter.

woman, is further noteworthy as the oldest boat burial in Norway, and approximately contemporary with the sixth-century boat grave in Suffolk. This mode of burial seems to have been the logical outcome of the Charon belief, evidences of which are found about this time in the form of ferry money. Rooting itself naturally and growing exuberantly in the mind of a seafaring folk, this rite bore its richest fruit in the subsequent Viking period, when the gross materialisation of a more primitive symbolism reached its climax. Towards that neriod there are also observed an increase in the number of weapons, a decrease in the size of No. 2267 , voL. 9I] the mounds, and a tendency to uniformity of style throughout the whole of the north.

Usually in the Viking period there was a funeral pyre on a flat surface, below which the grave was dug and afterwards filled in with large stones, while its position might be marked by one or more gravestones (Fig. 2). The older orientation of head to north was often departed from. This last change and the increased simplicity may betoken Christian customs, if not actually Christian faith. But the halls of the mighty were still homes of heathen worship; their bodies lay when dead with head true to the north of their fathers, and over them, as at Upsala, at Tune, or at Gunnarshaug, were piled the highest mounds with the richest store of goods and the hugest sacrifices known from all Scandinavia.

\section{MIGRATIONS OF BIRDS. ${ }^{2}$}

THE volume before us is the seventh of the series of annual reports on migration which we owe to the industry of a committee of the British Ornithologists' Club, which has set itself the task of collecting evidence over a period of ten years, and thereafter of summarising the data thus obtained. The reports have increased progressively both in scope and bulk, and the one before us is a stout volume. It deals mainly with the immigratory movements of birds visiting England and Wales for the purpose of nesting in the summer of IgIr. Passage movements are also dealt with, and the autumn movements of I9Io as reported by lighthouses and light-vessels. Summaries of the meteorological conditions are furnished for purposes of comparison.

As the drawing of conclusions is forbidden by the self-denying ordinance of the committee, the volume before us is to be regarded as a summation of facts, and as such it deserves all praise, for everything possible has been done to ensure clearness by condensation, tabulation, and the addition of diagrammatic tables. An immense amount of material has had to be classified and arranged, and we think that the committee has chosen the best course in grouping its facts under the headings of species, although the initial chronological summary is perhaps the most interesting to the casual reader.

The spring migration commenced on March Io and continued until May 29. During the latter half of April there were three distinct waves of

1 Report on the Immigrations of Summer Residents in the Spring of IOII; also Notes on the Migratory Movements and Records received from I9II; also Notes on the Migratory Movements and Records received rom Lighthouses and Light-vessels during the Autumn of Igro. By the Com-

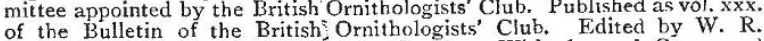
Ogilvie-Grant. Pp. $33^{2}+20$ maps. (London: Witherby and Co., 1912.)
Price $6 s$. 